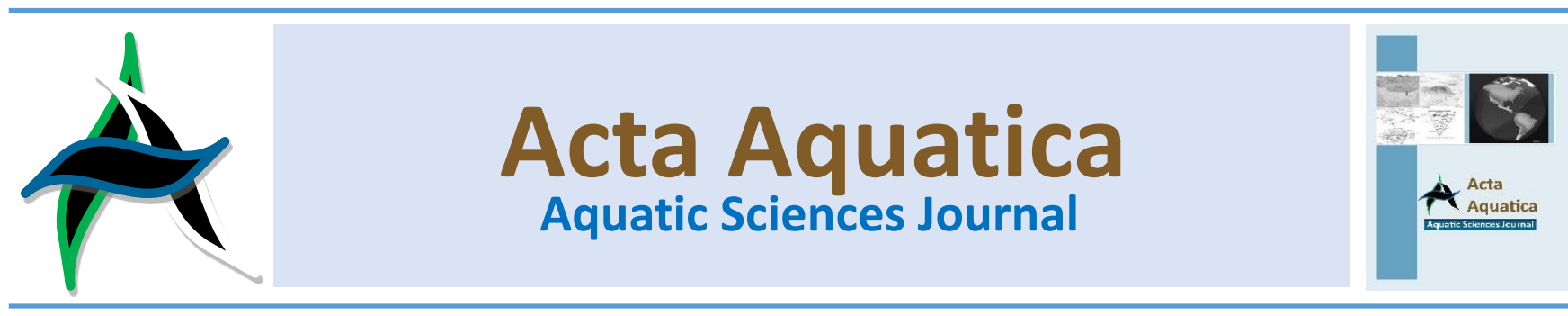

\title{
Penambahan nano CaO limbah cangkang kijing (Pilsbryocncha exilis) pada media bersalinitas untuk pertumbuhan ikan nila (Oreochromis niloticus)
}

\section{Addition of nano $\mathrm{CaO}$ from mussel (Pilsbryocncha exilis) shell waste on the salinity media for tilapia (Oreochromis niloticus) growth}

\author{
Asmaini ${ }^{a}$, Lia Handayani ${ }^{b}$ dan Nurhayati ${ }^{a}$ \\ ${ }^{a}$ Program Studi Budidaya Perairan, Fakultas, Perikanan. Universitas Abulyatama. Aceh, Indonesia. \\ ${ }^{b}$ Program Studi Teknologi Hasil Perikanan, Fakultas, Perikanan. Universitas Abulyatama. Aceh, Indonesia.
}

\begin{abstract}
Abstrak
Salinitas diperairan dapat menimbulkan tekanan osmosis yang berbeda dengan tekanan osmosis dalam tubuh organisme perairan. Ion $\mathrm{Ca}^{2+}$ merupakan salah satu ion yang terkandung dalam kadar salinitas yang menentukan tekanan osmosis. Tujuan dari penelitian ini adalah untuk mengetahui pengaruh penambahan nano kalsium cangkang kijing (NCCK) pada pakan dan lingkungan dalam pemeliharaan media bersalinitas $4 \mathrm{ppt}$. Penelitian ini dilakukan selama 40 hari dilaboratorium perikanan, Universitas Abulyatama. Berat rata-rata ikan pada awal penelitian yaitu 1,82 gram dengan jumlah ikan 648 ekor dengan menggunakan 9 akuarium yaitu 72 ekor/akuarium. Data dianalisis menggunakan uji $\mathrm{T}$ (perbandingan) antara ikan nila tanpa penambahan NCCK pada pakan dan lingkungan (A) dengan penambahan NCCK sebanyak $2 \%$ pada pakan (B) dan penambahan NCCK sebanyak $40 \mathrm{mg} / \mathrm{L}$ pada lingkungan (C). Hasil yang diperoleh antara perbandingan A dan B adalah berpengaruh nyata terhadap pertumbuhan berat namun berpengaruh terhadap pertumbuhan panjang dan kelangsungan hidup. Untuk uji T antara perlakuan A dan C berpengaruh nyata terhadap pertumbuhan panjang dan kelangsungan hidup, namun tidak berpengaruh terhadap pertumbuhan berat. Sedangkan untuk uji T antara perlakuan B dan C berpengaruh nyata terhadap kelangsungan hidup namun tidak berpengaruh terhadap pertumbuhan berat dan panjang. Kalsium mempunyai peran penting dalam proses osmoregulasi pada ikan, dengan adanya penambahan kalsium dapat mempercepat osmoregulasi. Hasil uji kadar kalsium $\left(\mathrm{Ca}^{2+}\right)$ dengan proses kalsinasi menggunakan metode AAS (Atomic Absortion Spectrophotometer) adalah $77,15 \%$.
\end{abstract}

\begin{abstract}
Water salinity can cause osmotic pressure which is different from the osmotic pressure that occurs in the body of the aquatic organisms. The $\mathrm{Ca}^{2+}$ ion is one of the ions contains in salinity which can initiate the osmotic pressure. This study aims to find out the effect of nano calcium addition from the mussel shell (NCCK) in the fish feed and the environment in the $4 \mathrm{ppt}$ salinity media. This research was done for 40 days in a fishery laboratory, Abulyatama University. The average weight of fish at the study was 1.82 grams, with the number of fish 648 using 9 aquariums that is 72 fish/aquarium. The data were analyzed using the t-test (comparison) between (A) tilapia without the addition of NCCK in the fish feed and environment, (B) tilapia with the $2 \%$ addition of NCCK in the fish feed, (C) tilapia with the $40 \mathrm{mg} / \mathrm{L}$ addition of NCCK in the environment (C). The result obtained from the ratio of $A$ and $B$ shows a significant effect on fish weight growth. However, this result did not affect the fish length and survival rate. Moreover, the result from the t-test between $A$ and $C$ also shows a significant effect on the length and survival rate. Nevertheless, this result did not affect fish weight growth. Further, the t-test between $B$ and $C$ shows a significant effect on the survival rate but did not have any effect on the fish growth both in weight and length. Calcium has an essential role in the osmoregulation process in fish, with the addition of calcium can accelerate osmoregulation. The result of the Calcium $\left(\mathrm{Ca}^{2+}\right)$ test with the calcination process using the Atomic Absorption Spectrophotometer (AAS) method was $77.15 \%$.
\end{abstract}

Keywords: mussel shell; nano CaO; osmoregulation; salinity 


\section{Pendahuluan}

Ikan nila (Oreochromis niloticus) merupakan salah satu jenis ikan air tawar yang populer di kalangan masyarakat. Sehingga menjadikan ikan nila bernilai prospek yang cukup menjanjikan. Apabila ditinjau dari segi pertumbuhan, ikan nila merupakan jenis ikan yang memiliki laju pertumbuhan yang cepat dan dapat mencapai bobot tubuh yang jauh lebih besar dengan tingkat produktivitas yang cukup tinggi.Namun budidaya ikan nila masih mengalami kendala seperti biaya pakan yang cukup tinggi karena masa pemeliharaan yang lama dan tingkat pertumbuhan yang lambat.

Salinitas merupakan salah satu parameter lingkungan yang mempengaruhi proses biologi suatu organisme dan secara langsung akan mempengaruhi kehidupan organisme antara lain mempengaruhi laju pertumbuhan, jumlah makanan yang dikonsumsi (konversi makanan) dan kelangsungan hidup. Salinitas sebagai salah satu parameter kualitas air yang mempengaruhi tekanan osmotik cairan tubuh ikan nila, maka tekanan osmotik media akan menjadi beban bagi ikan nila sehingga dibutuhkan energi yang relatif besar untuk mempertahankan osmotik tubuhnya melalui proses osmoregulasi agar berada tetap pada keadaan yang ideal.

Media bersalinitas mempengaruhi sistem osmoregulasi dalam tubuh ikan. Cairan tubuh ikan air tawar mempunyai tekanan yang lebih tinggi (hiperosmotik) daripada lingkungannya sehingga cenderung mengambil garam-garam dari air melalui difusi. Kalsium juga memiliki fungsi untuk pembentukan tulang, metabolisme, dan permeabilitas membran. Kebutuhan kalsium pada ikan berkisar antara 5 gram/kg pakan.

Salah satu hewan perairan yang dapat digunakan sebagai sumber kalsium yang digunakan pada penelitian ini adalah cangkang dari jenis kerang-kerangan, yaitu cangkang kijing lokal (Pilsbryocncha exilis). Kijing lokal (Pilsbryocncha exilis) merupakan salah satu komunitas perairan kerang air tawar yang digemari masyarakat. Umumnya masyarakat mengkonsumsi kijing berupa dagingnya, cangkang kijing lokal banyak yang terbuang sehingga menghasilkan limbah padat yang cukup tinggi, salah satu upaya mengurangi limbah padat tersebut adalah mengolah limbah cangkang kijing menjadi sumber kalsium.

Mineral berukuran mikro dapat terabsorbsi hanya $50 \%$ sehingga sering menyebabkan defisiensi. Sedangkan ukuran nano dapat menyebabkan reseptor cepat masuk kedalam tubuh dengan sempurna, oleh karena itu kalsium dengan ukuran nano dapat terabsorbsi oleh tubuh hampir 100\% (Suptijah, 2009). Pemanfaatan cangkang kerang-kerangan sebagai sumber kalsium telah banyak dilakukan diantaranya cangkang tiram (Handayani, 2018; Fitriana et al., 2019).

Berdasarkan uraian di atas penulis tertarik untuk menggabungkan mineral nano kalsium dari cangkang kijing kedalam pakan komersial. Sehingga mineral nano kalsium cangkang kijng yang ditambahkan dalam pakan komersial untuk pembentukan tulang dan pertumbuhan pada ikan nila. Oleh sebab itu penulis tertarik untuk melakukan penelitian "Penambahan nano CaO limbah cangkang kijing (Pilsbryocncha exilis) pada media bersalinitas untuk pertumbuhan benih ikan nila (Oreochromis niloticus)". Penelitian ini bertujuan untuk mengetahui pengaruh pemberian nano $\mathrm{CaO}$ cangkang kijing (NCCK) kedalam pakan dan lingkungan terhadap pertumbuhan serta kelangsungan hidup ikan nila pada media bersalinitas.

\section{Bahan dan metode}

\subsection{Waktu dan tempat}

Penelitian ini dilaksanakan di Laboratorium Terpadu Fakultas Perikanan Universitas Abulyatama. Penelitian ini dilaksanakan tanggal 5 Juli sampai 15 Agustus 2019.

\subsection{Alat dan bahan}

Bahan Ikan Nila, cangkang kijing, dan pellet. Sedangkan alat yang digunakan dalam penelitian ini adalah ikan nila, cangkang kijing, pellet, akuarium, serok, penggaris, timbangan, kamera, alat tulis.

\subsection{Rancangan penelitian}

Rancangan percobaan yang digunakan adalah dengan perbandingan yaitu menggunakan uji T dengan mengaplikasikan 3 perlakuan 3 kali ulangan. Uji T yang dilakukan adalah dengan membandingkan hasil perlakuan A dan B, Pelakuan A dan C, dan perlakuan $B$ dan $C$. Penelitian ini menggunakan media berupa air tawar dan air laut, dimana untuk mendapatkan salinitas 4 ppt dilakukan pengenceran air laut

\subsection{Prosedur penelitian}

Pembuatan nanokalsium

Cangkang kijing yang diperoleh dari hasil limbah kemudian di cuci hingga bersih, setelah itu cangkang yang dibersihkan dan dijemur di bawah terik matahari selama 1 minggu, kemudian dilakukan pengecilan ukuran sampai dengan ukuran kacang hijau, tujuan pengecilan ukuran agar mudah dalam proses penghalusan, selanjutnya cangkang dihaluskan 200 mesh (Gambar 1).



Gambar 1. Bagan alir pembuatan NCCK dan aplikasinya 
Kemudian $\mathrm{CaO}$ yang dihasilkan akan di kalnisasi pada suhu 900 C selama 4 jam, rendamen kalsinasi cangkang kijing menjadi $\mathrm{CaO}$ diperoleh sebesar 63,80\%, lalu ditambahkan kedalam pakan sebanyak $2 \%$ dan dicampurkan dengan bahan pakan yang sudah disiapkan. Untuk pakan kontrol tidak ditambahkan mineral nano NCCK. Selanjutnya siap diaplikasikan ke hewan uji. Kadar kalsium pada NCCK setelah melalui uji AAS adalah sebesar 77,15\%. 2\% kapur CaO di tambahkan kedalam pakan dengan jumlah 500 gram, ditambahkan CMC 1\%, lalu ditambahkan air 20\%, diaduk rata, kemudian setelah NCCK dan bahan tambahan lainnya merata didalam pakan, dlakukan repleting (cetak ulang pakan). Kemudian pakan di jemur 4 hari setelah kering, pakan hasil repleting dengan penambahan NCCK siap di aplikasikan ke hewan uji. Selanjutnya 0\% digunakan sebagai pakan kontrol (tanpa menggunakan NCCK).

\subsection{Parameter uji}

\section{Tingkat kelangsungan hidup}

Tingkat kelangsungan hidup atau survival rate (SR) diukur dengan menggunakan rumus menurut Effendie (1997):

$$
\mathrm{SR}=(\mathrm{Nt} / \mathrm{No}) \times 100 \%
$$

Keterangan:

$\mathrm{SR}=$ Kelangsungan hidup benih (\%)

$\mathrm{Nt}=$ Jumlah ikan pada akhir penelitian (ekor)

No = Jumlah ikan pada awal penelitian (ekor)

Pertumbuhan bobot mutlak

Pertumbuhan bobot mutlak ikan dihitung dengan mengikuti rumus Effendie (1997) sebagai berikut:

$$
W m=W t-W o
$$

Keterangan:

Wm $=$ Pertumbuhan berat mutlak $(\mathrm{g})$

$\mathrm{Wt}=$ Bobot akhir (g)

Wo = Bobot awal $(\mathrm{g})$

\section{Pertumbuhan panjang mutlak}

Pertumbuhan mutlak didefinisikan sebagai pertumbuhan total dari jurnal bobot akhir dikurangi panjang bobot awal. Pertumbuhan panjang mutlak ikan uji dihitung mengikuti rumus yang digunakan oleh Effendie (1997):

Keterangan:

$$
\mathrm{L}=\mathrm{Lt}-\mathrm{Lo}
$$

$\mathrm{L} \quad=$ Pertumbuhan panjang mutlak $(\mathrm{cm})$

Lt $\quad$ Panjang rata-rata individu pada akhir penelitian $(\mathrm{cm})$

Lo = Panjang rata-rata individu pada awal penelitian $(\mathrm{cm})$

Laju pertumbuhan harian (\%/hari)

Laju pertumbuhan harian (specific growth rate) untuk menghitung laju pertumbuhan harian menurut Effendie (1997) menggunakan rumus sebagai berikut:

$$
S G R=\operatorname{Ln} W t-\operatorname{Ln} \text { Wo } \times 100 / t
$$

Keterangan:

SGR = Laju pertunbuhan spesifik (\%hari)

$\mathrm{Wt}=$ Bobot biomass ikan uji pada akhir penelitian (g)

Wo = Bobot biomass ikan uji pada akhir penelitian (g)

$\mathrm{t} \quad=$ Waktu pemeliharaan (hari)
Rasio konversi pakan

Menurut Sugiyono (2010), rasio konversi pakan atau food conversion ratio (FCR) dihitung berdasarkan rumus:

$$
F C R=F /(W t+D)-W o
$$

Keterangan:

$\mathrm{FCR}=$ Rasio konvers

$F \quad=$ Berat pakan yang diberikan $(\mathrm{g})$

$\mathrm{Wt}=$ Biomassa hewan uji pada akhir penelitian (g)

$D \quad=$ Bobot udang mati $(\mathrm{g})$

Wo = Biomassa hewan uji pada awal penelitian (g)

Efesiensi pakan

Rumus yang digunakan untuk menghitung efisiensi pakan meurut Afrianto dan Liviawaty (2005) adalah:

$$
E P=((W t+D)-W o / F) \times 100 \%
$$

Keterangan:

EP : Efisiensi pakan (\%)

Wt ; Bobot ikan akhir (g)

Wo : Bobot ikan awal (g)

D : Bobot ikan mati (g)

$\mathrm{F} \quad$ : Jumlah pakan dikonsumsi $(\mathrm{g})$

\section{Hasil dan pembahasan}

Kalsium mempunyai peran penting dalam proses pembentukan tulang, metabolisme, dan permeabilitas membran. Dengan adanya penambahan kalsium dapat mempercepat proses pembentukan tulang, metabolisme, dan permeabilitas membran.

Berdasarkan hasil yang di peroleh selama 40 hari penelitian menunjukkan bahwa penambahan kalsium pada pakan sebanyak $2 \%$ merupakan hasil terbaik untuk pertumbuhan berat dan kelangsungan hidup. Sedangkan untuk pertumbuhan harian dan pertumbuhan panjang hasil terbaik adalah pada pakan control (Tabel 1).

Tabel 1

Hasil penelitian terhadap parameter pengamatan.

\begin{tabular}{lccc}
\hline \multirow{1}{*}{ Parameter } & \multicolumn{3}{c}{ Perlakuan } \\
\cline { 2 - 4 } & A (nilai \pm stdev) & B (nilai \pm stdev) & C (nilai \pm stdev) \\
\hline $\begin{array}{l}\text { Kelangsungan } \\
\text { hidup (\%) }\end{array}$ & $96,52 \pm 0,98$ & $97,22 \pm 0$ & $95,13 \pm 2,94$ \\
$\begin{array}{l}\text { Pertumbuhan } \\
\text { bobot mutlak (g) }\end{array}$ & $2,6 \pm 0,46$ & $2,67 \pm 0,09$ & $2,41 \pm 0,04$ \\
$\begin{array}{l}\text { Pertumbuhan } \\
\text { panjang }\end{array}$ & $1,85 \pm 0,38$ & $1,68 \pm 0,02$ & $1,69 \pm 0,06$ \\
$\begin{array}{l}\text { mutlak(cm) } \\
\text { Spesific growth } \\
\text { rate (\%/hari) }\end{array}$ & $2,48 \pm 0,24$ & $2,24 \pm 0,09$ & $2,12 \pm 0,05$ \\
$\begin{array}{l}\text { Rasio konversi } \\
\text { pakan }\end{array}$ & $3,30 \pm 0,00$ & $3,24 \pm 0,00$ & $3,41 \pm 0,00$ \\
$\begin{array}{l}\text { Efisiensi pakan } \\
\text { (\%) }\end{array}$ & $30,28 \pm 0,12$ & $30,84 \pm 0,01$ & $29,32 \pm 0,01$ \\
\hline $\begin{array}{l}n \text { (ulangan) }=3 \\
\text { malan }\end{array}$ & & &
\end{tabular}

\subsection{Tingkat kelangsungan hidup}

Tingkat kelangsungan hidup ikan nila pada berbagai media salinitas tersebut, menunjukkan bahwa ikan nila bersifat euryhalin. Hepher dan Priguinin, (1999) menyatakan bahwa spesies ikan nila mampu beradaptasi pada media bersalinitas tinggi, karena media bersalinitasnya cukup baik. Perbedaan tingkat kelangsungan hidup menunjukkan bahwa ikan nila yang dipelihara pada media bersalinitas lebih baik dalam memanfaatkan sumber energi pakannya dan diduga pada media 
salinitas 0 ppt-30 ppt kondisi tekanan osmotik media mendekati tekanan osmotik ikan nila atau disebut isoosmotik.

Laju kelangsungan hidup ikan nila selama penelitian menunjukkan bahwa penambahan nanokalsium dari cangkang kijing $2 \%$ pada pakan lebih tinggi di bandingkan dengan penambahan pada lingkungan $40 \mathrm{mg} / \mathrm{l}$ dan kontrol. Laju kelangsungan hidup pada perlakuan $\mathrm{B}$ dengan penambahan $2 \%$ yaitu $97,22 \%$, kemudian di ikuti oleh perlakuan A sebagai kontrol yaitu $96,52 \%$, kemudian yang terendah pada perlakuan $C$ dengan penambahan nano lingkungan $40 \mathrm{mg} / \mathrm{l}$ yaitu 95,13\%. Holliday (1996) bahwa ikan mampu bertahan pada media bersalinitas tergantung pada kemampuan untuk mengatur cairan tubuh sehingga mampu mempertahankan tingkat tekanan osmotik yang mendekati normal. Untuk ikan ikan euryhalin, memiliki kemampuan yang cepat menyeimbangkan tekanan osmotik dalam tubuhnya dengan media. Tingkat kelangsungan hidup sangat menentukan hasil dari produksi budidaya (Effendi, 2004).

\subsection{Pertumbuhan}

Pertumbuhan harian adalah persentase pertambahan pertumbuhan tiap selang waktu. Pertumbuhan harian ikan nila selama masa penelitian tertinggi terjadi pada perlakuan $A$ (kontrol) 2,48 gr, sedangkan pada perlakuan B (2\% NCCK) 2,24 gr, kemudian nilai terendah pada perlakuan C (40 mg/l NCCK) dengan pertumbuhan berat harian sebesar 2,12 gr. Perbedaan pertumbuhan pada media bersalinitas yang berbeda diduga terkait dengan tekanan osmotik cairan tubuh dan lingkungan. Semakin jauh perbedaan tekanan osmotik tubuh dengan tekanan osmotik lingkungan, maka akan semakin banyak beban kerja energi metabolisme yang dibutuhkan untuk melakukan osmoregulasi sebagai upaya adaptasi pada lingkungan yang bersalinitas (Fujaya, 2004).

Pertumbuhan bobot mutlak diperoleh dari hasil pengukuran berat tubuh ikan dilakakan setiap 10 hari sekali selama penelitian. Untuk pertumbuhan bobot mutlak terbaik diperoleh dari perlakuan B ( $2 \%$ NCCK) 2,67 gr/ekor, kemudian diikuti oleh perlakuan C (40 mg/l NCCK) 2,41 gr/ekor dan pada perlakuan A (kontrol) 2,6 gr/ekor. Pemberian NCCK 2\% dalam pakan berpengaruh nyata terhadap pertumbuhan bobot ikan nila.

Pertumbuhan bobot mutlak diperoleh dari hasil pengukuran berat tubuh ikan dilakakan setiap 10 hari sekali selama penelitian. Untuk pengukuran panjang mutlak terbaik diperoleh dari perlakuan A (kontrol) $1,85 \mathrm{~cm}$, diikuti oleh perlakuan C (40 mg/l NCCK) 1,69 cm dan di perlakuan B $(2 \%$ NCCK) $1,68 \mathrm{~cm}$. Pemberian NCCK $2 \%$ dalam pakan tidak berpengaruh terhadap pertumbuhan panjang ikan nila. Menurut penelitian Handayani dan Syahputra (2018) penambahan nanokalsium pada pakan lobster air tawar dapat meningkatkan pertumbuhan, begitu pula dengan hasil penelitian lainnya yang menyebutkan bahwa penambahan nanokalsium cangkang tiram pada udang galah dapat meningkatkan frekuensi molting (Handayani \& Syahputra 2018). Selain itu, penambahan kalsium dari tulang ikan kambing-kambing (Aceh: leubim) dapat meningkatkan pertumbuhan udang galah (Restari et al., 2019). Cangkang kepiting yang dimanfaatkan menjadi nanokalsium (Zulfadhillah, et al., 2018) dan sebagai kalsium (Handayani \& Fajri, 2019) berpengaruh terhadap pertumbuhan udang galah dengan penambahan sebanyak $2 \%$.

Menurut Prihadi (2007), pertumbuhan dipengaruhi oleh beberapa faktor yaitu faktor internal dan faktor eksternal, adapun faktor dari dalam meliputi sifat keturunan, ketahanan terhadap penyakit dan kemampuan dalam memanfaatkan makanan, sedangkan dari luar meliputu sifat fisika, kimia dan biologi perairan. Faktor makanan dan suhu perairan merupakan faktor utama yang dapat mempengaruhi pertumbuhan ikan. Karena suhu yang tinggi dapat mengurangi oksigen terlarut sehingga selera makan ikan terganggu. Perbedaan suhu air media dengan tubuh ikan akan menimbulkan gangguan metabolisme. Kondisi ini dapat mengakibatkan sebagian besar energi yang tersimpan dalam tubuh ikan digunakan untuk penyesuaian diri terhadap lingkungan yang kurang mendukung tersebut, sehingga dapat merusak sistem metabolisme atau pertukaran zat (Emaliana et al., 2010).

\subsection{Rasio konversi pakan}

Konversi pakan merupakan perbandingan antara jumlah pakan yang diberikan dengan jumlah bobot ikan yang dihasilkan. Menurut (Susanti, 2004) semakin kecil nilai konversi pakan semakin baik, sebaliknya apabila konversi pakan besar maka tidak efisien. Berdasarkan hasil pengamatan yang dilakukan selama penelitian 40 hari, nilai rasio konversi pakan yang terbaik terdapat pada perlakuan B (2\% NCCK) 3,2424 diikuti perlakuan A (kontrol) 3,3019 dan pada perlakuan C (40 mg/l NCCK) 3,4101. Hasil penelitian Arsyal et al. (2013) sebesar 1,25 dan hasil penelitian Putri et al. (2012) sebesar 3,36. Menurut Mudjiman (2011), konversi makanan pada ikan berkisar 1,5-8 bearti nilai konversi pakan pada semua perlakuan dapat dikatakan baik, karena pakan yang diberikan benar-benar dapat di manfaatkan oleh ikan untuk pertumbuhan bobot yang maksimal. Hal tersebut juga terlihat dari hasil penelitian Nurhayati dan Nazlia (2019) rasio konversi pakan bernilai 4 hingga 13. Hal ini diduga bahwa ikan nila tidak maksimal dalam mengkonversi pakan dengan kandungan abu yang tinggi.

\subsection{Efisiensi pakan}

Nilai efisiensi pakan diperoleh dari hasil perbandingan antara pertambahan bobot tubuh ikan dengan jumlah pakan yang dikonsumsi oleh ikan selama masa penelitian. Berdasarkan hasil pengamatan yang dilakukan selama penelitian 40 hari, nilai efisiensi pakan terbaik terdapat pada perlakuan B ( $2 \%$ NCCK) $30,84 \%$, diikuti perlakuan A (kontrol) 30,28 \% dan pada perlakuan C (40 mg/I NCCK) 29,32\% (Tabel 2).

Tabel 2

Perbandingan $t_{\text {hitung }}$ dengan $t_{\text {tabel }} 5 \%(2,30)$.

\begin{tabular}{lccc}
\hline \multirow{2}{*}{ Parameter } & \multicolumn{3}{c}{ Uji } \\
\cline { 2 - 4 } & $\mathrm{A}-\mathrm{B}$ & $\mathrm{A}-\mathrm{C}$ & $\mathrm{B}-\mathrm{C}$ \\
\hline Kelangsungan & $t_{\text {hitung }} 1,63<\mathrm{t}_{\text {tabel }}$ & $t_{\text {hitung }} 3,43>$ & $t_{\text {hitung }} 3,13>$ \\
hidup & 2,30 & $\mathrm{t}_{\text {tabel }} 2,30$ & $\mathrm{t}_{\text {tabel }} 2,30$ \\
Pertumbuhan & $\mathrm{t}_{\text {hitung }} 2,51>\mathrm{t}_{\text {tabel }}$ & $t_{\text {hitung }} 1,07<$ & $t_{\text {hitung }} 0,95<$ \\
berat & 2,30 & $\mathrm{t}_{\text {tabel }} 2,30$ & $\mathrm{t}_{\text {tabel }} 2,30$ \\
Pertumbuhan & $\mathrm{t}_{\text {hitung }} 2,20<\mathrm{t}_{\text {tabel }}$ & $t_{\text {hitung }} 2,38>$ & $t_{\text {hitung }} 1,44<$ \\
panjang & 2,30 & $\mathrm{t}_{\text {tabel }} 2,30$ & $\mathrm{t}_{\text {tabel }} 2,30$ \\
\hline
\end{tabular}

Menurut Kordi (2011) semakin besar nilai efisiensi pakan, berarti semakin efisien ikan memanfaatkan pakan yang dikonsumsi untuk pertumbuhannya. Hasil penelitian (Noviana et al., 2014) sebesar $77,23 \%$ dan penelitian (Anggriani et al., 2012) sebesar $69,62 \%$.

Penelitian ini menggunakan media bersalinitas $4 \mathrm{ppt}$ karena kadar garam pada salinat 4 ppt tidak terlalu tinggi sehingga ikan tidak membutuhkan energi yang berlebihan untuk mengambil kadar garam pada lingkungnnya. Jika salinitas terlalu tinggi ikan membutuhkan energi yang banyak untuk menyesuaikan dengan lingkungannya. Secara umum energi dibutuhkan oleh semua makhluk hidup untuk memelihara dan menjaga keseimbangan tubuhnya. 
Besarnya energi yang dibutuhkan tergantung dari kemampuan ikan dalam menyesuaikan diri dengan lingkungan dan besarnya konsumsi (energi) yang masuk dalam tubuh ikan. Kondisi tersebut menyebabkan terhambatnya pertumbuhan ikan atau menurunnya laju pertumbuhan karena kurangnya energi yang tersedia untuk pertumbuhan. Stickney (1997), menyatakan bahwa ikan yang dipelihara pada kondisi salinitas yang sama dengan kosentrasi ion dalam darah akan lebih banyak menggunakan energi untuk pertumbuhan sedangkan semakin tinggi perbedaan antara kondisi salinitas dengan kosentrasi ion dalam darah maka ikan cenderung akan terganggu pertumbuhannya bahkan mengalami kematian.

Osmoregulasi pada ikan adalah upaya ikan mengontrol keseimbangan air dan ion antara didalam tubuh dan lingkungan melalui mekanisme pengaturan tekanan osmotik (Marsyal et al., 2006). Selanjutnya menyatakan bahwa ginjal akan memompakan kelebihan air tersebut sebagai air seni. Ginjal mempunyai glomeruli dalam jumlah yang banyak dengan diameter yang besar. Hal ini bertujuan untuk menahan garamgaram tubuh agar tidak keluar dan sekaligus memompa air seni sebanyak-banyaknya. Air seni yang keluar dari tubuh ikan sangat encer dan mengandung sejumlah kecil senyawa nitrogen. Proses osmoregulasi juga menghasilkan produk buangan seperti fases dan amoniak, sehingga media pemeliharaan akan bewarna keruh sebagai akibat banyak fases yang dikeluarkan ikan. Proses osmoregulasi juga dipengaruhi kosentrasi ion-ion divalen $\left(\mathrm{Ca}_{2} \mathrm{C}\right.$ dan $\left.\mathrm{Mg}_{2} \mathrm{C}\right)$ karena pengaruhnya terhadap membran permeabel dan osmoregulasi. Kosentrasi kalsium yang tinggi di lingkungan membantu mengurangi kehilangan garam melalui insang dan permukaan tubuh pada lingkungan perairan tawar, sehingga sedikit kerja ginjal untuk menjaga kosentrasi garam-garam dalam darah. Perubahan kadar salinitas mempengaruhi tekanan osmotik cairan tubuh ikan, sehingga ikan melakukan penyesuaian atau pengaturan kerja osmotik internalnya agar proses fisiologis didalam tubuhnya dapat bekerja secara normal kembali (Stickney, 1997).

\subsection{Karakteristik kalsium}

Kalsium mempunyai peran penting dalam proses osmoregulasi pada ikan, dengan adanya penambahan kalsium dapat mempercepat osmoregulasi. Hasil uji kadar kalsium (Ca) dengan proses kalsinasi menggunakan metode AAS (Atomic Absortion Spectrophotometer) menunjukkan bahwa kadar kalsium adalah sebesar $77,15 \%$. Hasil penelitian Handayani et al. (2019) menunjukkan bahwa kandungan kalsium yang terdapat pada cangkang langkitang adalah sebesar $33 \%$. Handayani dan Syahputra (2017) mengatakan bahwa kandungan kalsium cangkang tiram berkisar $56,77 \%$. Rahayu et al. (2018) mengatakan bahwa kandungan dalam cangkang kerang mutiara yaitu $52,23 \%$. Wardhani (2009) menyatakan bahwa kandungan kalsium karbonat pada tepung cangkang kijing ukuran $<90 \mathrm{~mm}$ sebesar $39,55 \%$.

Identifikasi gugus fungsi pada suatu molekul dapat ditentukan dengan mengukur serapan infra merah. Pada panjang gelombang $3387 \mathrm{~cm}^{-1}$ muncul pita serapan disebabkan oleh gugus fungsi $\mathrm{OH}$. Pada panjang gelombang $2515 \mathrm{~cm}^{-1}$ yang menunjukkan adanya gugus fungsi $\mathrm{CH}$. Pita serapan yang muncul pada bilangan gelmbang $1782 \mathrm{~cm}^{-1}$ disebabkan oleh vibrasi peregangan gugus fungsi $\mathrm{C}=\mathrm{O}$ amida sekunder. Pita serapan selanjutnya muncul pada bilangan $1485 \mathrm{~cm}^{-1}$ yang disebabkan oleh gugus fungsi $\mathrm{C}-\mathrm{O}$. Sementara serapan yang terbentuk pada bilangan gelombang $860 \mathrm{~cm}^{-1}$ merupakan akibat adanya gugus $\mathrm{C}-\mathrm{O}-\mathrm{C}$. Sedangkan serapan yang terbentuk pada gelombang $705 \mathrm{~cm}^{-1}$ merupakan gugus SiO.

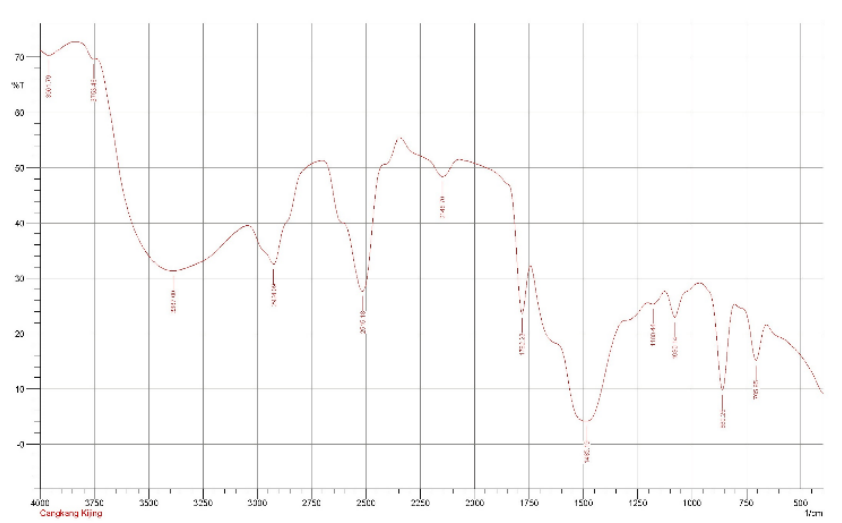

Gambar 2. Hasil analisa FTIR cangkang kijing

\subsection{Kualitas air}

Air merupakan media atau habitat yang paling penting bagi kehidupan ikan. Suplai air yang memadai akan memecahkan berbagai masalah dalam budidaya ikan. Selain itu, kualitas air yang baik merupakan salah satu kunci keberhasilan dalam budidaya ikan. Suhu mempengaruhi aktifitas ikan seperti pernapasan dan reproduksi (Huet, 1997). Suhu air sangat berkaitan erat dengan kosentrasi oksigen terlarut dan laju konsumsi oksigen hewan air. Suhu air media selama penelitian masih berada dalam kisaran yang optimum untuk kehidupan ikan nila (Oreochromis niloticus).

Berdasarkan hasil pengukuran suhu dalam penelitian ini berlangsung berkisar antara $26 \stackrel{\circ}{\circ}-28^{\circ} \mathrm{C}$. Kisaran suhu tersebut masih optimum untuk pertumbuhan ikan nila. Menurut Suyanto (1997) bahwa suhu optimal untuk pertumbuhan ikan nila antara $25 \stackrel{\circ}{\circ}-30 \stackrel{\circ}{\circ}$. Suhu air berpengaruh terhadap nafsu makan dan proses metabolisme ikan. Pada suhu rendah proses pencernaan makanan pada ikan berlangsung lambat, sedangkan pada suhu hangat proses pencernaan berlangsung lebih cepat. Karena pada saat suhu meningkat maka akan meningkatkan pengambilan makanan pengambilan makanan oleh ikan dan turunnya suhu menyebabkan metabolisme akan berjalan lambat (Effendi, 2003).

Derajat keasaman $\mathrm{pH}$ dalam penelitian ini berkisar antara $7,4-7,7$. Kisaran $\mathrm{pH}$ tersebut merupakan kondisi yang baik untuk habitat dan pertumbuhan ikan nila. Menurut Rukmana (1997), kisaran $\mathrm{pH}$ untuk pertumbuhan optimalnya terjadi pada $\mathrm{pH} 7-8$, Sedangkan $\mathrm{pH}$ untuk habitat ikan nila antara 6-8,5. Pengaruh $\mathrm{pH}$ perairan dapat terjadi pada kelangsungan hidup dan pertumbuhan ikan. Tinggi rendahnya $\mathrm{pH}$ diluar kisaran toleransi ikan menyebabkan rendahnya bobot akhir dan pada nilai pH ekstrim bias mengganggu ikan (Hepher \& Pruginin, 1999)

\section{Kesimpulan}

Dari hasil penelitian penambahan NCCK kijing (Pilsbryocncha exilis) pada media bersalinitas berpengaruh terhadap pertumbuhan dan kelangsungan hidup ikan nila (Oreochromis niloticus). Penambahan nanokalsium cangkang kijing pada pakan tidak berbeda nyata terhadap pertumbuhan, dan berbeda nyata terhadap kelangsungan hidup ikan nila. Sementara pada lingkungan berbeda nyata terhadap pertumbuhan dan kelangsungan hidup ikan nila.

\section{Bibliografi}

Afrianto, E., Liviawaty, E., 2005. Pakan Ikan. Penerbit Kanasius. Yogyakarta. 
Anggriani, R., Iskandar. A., Taofiqurohman, 2012. Efektifitas Penambahan Bacillus sp. Hasil Isolasi Dari Saluran Pencernaan Ikan Patin pada Pakan Komersial terhadap Kelangsungan Hidup dan Pertumbuhan Benih Ikan Nila Merah (Oreochromis niloticus), FPIK, UNPAD. Bandung. Jurnal Perikanan dan Kelautan. 3 (3): 75-83.

Arsyal, R.A., 2013. Kajian Aplikasi Probiotik Yang Dibuat Dari Bahan Baku Lokal Terhadap Pertumbuhan dan Tingkat Kelangsungan Hidup Benih Ikan Nila (Oreochromis niloticus). Jurusan Budidaya Perairan Fakultas Perikanan dan Ilmu Kelautan Universitas Negeri Gorontalo.

Effendie, M.I., 1997. Biologi Perikanan. Yayasan Pustaka Nusantara, Yogyakarta.

Effendie, 2003. Kualitas air Bagi Pengelolaan Sumberdaya dan Lingkungan Perairan Yogyakarta: Kanisius.

Effendi, 2004. Biologi Ikan Nila. Yayasan Pustaka Nusatama. Jakarta. 54 hal.

Emaliana, S. Usman., Lesmana, I., 2010. Pengaruh Perbedaan Suhu terhadap Pertumbuhan Benih Ikan Mas Ko (cyprinus carpio). Universitas Sumatera Utara, Medan.

Fitriana, N., Handayani, L., Nurhayati, 2019. Penambahan nanokalsium cangkang tiram (Crassostrea gigas) pada pakan dengan dosis berbeda terhadap pertumbuhan udang galah (Macrobrachium rosenbergii). Acta Aquatica: Aquatic Sciences Journal, 6(2), 80-85.

Fujaya, Y., 2004. Fisiologi Ikan (Dasar pengembangan teknik perikanan). Rineka Cipta, Jakarta.

Handayani, L., Syahputra, F., 2017. Isolasi Dan Karakterisasi Nanokalsium Dari Cangkang Tiram (Crassostrea gigas). Jurnal Pengolahan Hasil Perikanan Indonesia (JPHPI), 20(3): 515-523.

Handayani, L., Syahputra, F., (2018). Perbandingan frekuensi molting Lobster air tawar (Cherax quadricarinatus) yang diberi pakan komersil dan nanokalsium yang berasal dari cangkang tiram (Crassostrea gigas). DEPIK Jurnal IImu-IImu Perairan, Pesisir dan Perikanan, 7(1), 42-46.

Handayani, L., Nurhayati, N., Nur, M., 2019. Perbandingan frekuensi molting udang galah (Macrobrachium rosenbergii de Man) yang diberi nano cao cangkang langkitang (faunus ater) pada pakan dan lingkungan. In Seminar Nasional Multi Disiplin IImu Universitas Asahan ke 3.

Handayani, L., Fajri, F., 2019. Penambahan mineral kalsium dari cangkang kepiting bakau (Scylla serrata) pada pakan terhadap pertumbuhan dan kelangsungan hidup udang galah (Macrobrachium rosenbergii). DEPIK Jurnal IImuIImu Perairan, Pesisir dan Perikanan, 8(3).

Hepher, B., Pruginin, Y., 1999. Commercial Fish Farming with Special Reference to Fish Culture in Israe/. John Willeyband Sons. New York.

Holliday, F.C.T., 1996. The Effect of Salinity on the Eggs and Larvae of Teleosts. In Hoar, W.S and D.J Randall (Eds). Fish Physiology, Vol. I. Academic Perss, New York.
Huet, M., 1997. Text book of fish culture, Breeding and Cultivation of fish. Fishing News, London.

Kordi, K., 2011. Panduan Lengkap Bisnis dan Budidaya Ikan Gabus. Lili Publisher. Yogyakarta.

Mudjiman, A., 2001. Makanan Ikan. Cet-XI. Penebar Swadaya Bogor.

Noviana, P., Subandiyono., Pinandoyo., 2014. Pengaruh Pemberian Probiotik dalam Pakan terhadap Tingkat Konsumsi Pakan dan Pertumbuhan Benih Ikan Nila (Oreochromis niloticus). Program Studi Budidaya Perairan, Jurusan Perikanan Fakultas Perikanan dan IImu Kelautan, Universitas Diponegoro. Semarang. Journal of Aquaculture Management and Technology, 3 (4): 183190.

Nurhayati, Nazlia, S., 2019. Aplikasi Tepung Daun Gamal (Gliricidia sepium) yang Difermentasi sebagai Penyusun Ransum Pakan terhadap Laju Pertumbuhan Ikan nila (Oreochromis niloticus). Jurnal Ilmiah Samudra Akuatika, 3(1), 6-11.

Prihadi, D. J., 2007. Pengaruh jenis dan waktu pemberian pakan terhadap tingkat kelangsungan hidup dan pertumbuhan kerapu macan (Epinephelus fuscoguttatus) dalam keramba jaring apung di Balai Budidaya Laut Lampung. Fakultas Perikanan dan IImu Kelautan Universitas Padjadjaran. Bandung. Jurnal Akuakultur Indonesia. 493 953.

Putri, S.F.Z., Hasan. K., Haetami, 2012. Pengaruh Pemberian Bakteri Probiotik Pada Pelet yang Mengandung Kaliandra (Calliandraca lothyrsus) Terhadap Pertumbuhan Benih Ikan Nila (Oreochromis niloticus). Jurnal Perikanan dan Kelautan. Vol 3 (4).

Rahayu, S., Kurniawidi, D.W., Gani, A., 2018. Pemanfaatan Limbah Cangkang Kerang Mutiara (Pinctada maxima) Sebagai sumber Hidroksiapatit. Jurnal Pendidikan Fisika dan Teknologi, 4(2): 226-231.

Restari, A. R., Handayani, L., Nurhayati, N., 2019. Penambahan Kalsium Tulang Ikan Kambing-kambing (Abalistes stellaris) pada pakan untuk keberhasilan gastrolisasi udang galah (Macrobrachium rosenbergii). Acta Aquatica: Aquatic Sciences Journal, 6(2), 69-75.

Rukmana, R.H., 1997. Budidaya dan Prospek Agribisnis. Kanisius. Yogyakarta

Stickney, R.R. 1997. Principle of Warmwater Aquaculture. John Willey and Sons Inc., New York.

Sugiyono, 2010. Statistika untuk Penelitian. Bandung, Alfabeta.

Suptijah, P., 2009. Sumber Nano Kalsium Hewan Perairan. Di dalam: 101 Inovasi Indonesia. Jakarta: Kementrian Negara, Riset dan Teknologi.

Susanti, D., 2004. Pengaruh Penambahan Berbagai pertumbuhan dan Kelulushidupan Benih Ikan Nila Gift [Skrpsi]. Universitas Diponegoro, $19 \mathrm{hlm}$.

Suyanto, R. S., 1997. Ikan Nila. Penebar Swadaya, Jakarta. 
Wardhani, Y.K., 2009. Karakteristik fisik dan kimia tepung cangkang kijing lokal (Pilsbryoconchaexilis sp) [skripsi]. Bogor: Fakultas Pertanian dan Ilmu Kelautan.

Zufadhillah, S., Thaib, A., \& Handayani, L., 2018. Efektivitas penambahan nano $\mathrm{CaO}$ cangkang kepiting bakau (Scylla serrata) kedalam pakan komersial terhadap pertumbuhan dan frekuensi molting udang galah (Macrobrachium rosenbergii). Acta Aquatica: Aquatic Sciences Journal, 5(2): 69-74. 